УДК 782.1

DOI: $10.17223 / 22220836 / 26 / 12$

\title{
Е.А. Приходовская
}

\section{ЭМОТИВНЫЙ ПЛАН - ПЕРВИЧНЫЙ СЮЖЕТ МОНООПЕРЫ}

\begin{abstract}
В статье излагается гипотеза, согласно которой моноопера представляет собой вериинное воплощение принципа психологической идентификации адресата и персонажа в искусстве. Первичным сюжетом (собственно «действием») в моноопере является хронологически выстроенная последовательность психологических событий внутреннего мира персонажа - эта последовательность обозначается как эмотивный план. Эмотивный план включает в себя эмотивные центры и эмотивы, как внетекстовые и внеязыковые, но смысловые категории - функиионируют эмотивные сферы, выступающие аналогом сил действия и контрдействия.

Ключевые слова: моноопера, эмотивность, психологическая идентификация, персонаж.
\end{abstract}

Проекция есть важнейшее свойство чувственных образов.

Л.М. Веккер

Согласно широко известному изречению Протагора «человек есть мера всех вещей существующих, что они существуют, и не существующих, что они не существуют». Любой человек, в чём можно убедиться на собственном опыте, воспринимает себя как «точку отсчёта» воспринимаемых им событий и явлений внешнего мира. Всё, что он видит, он «отмеряет» относительно себя самого, своего сознания и восприятия.

Философы задумывались об этом ещё в глубокой древности. В настоящее время данному явлению посвящён ряд исследований, например в сфере психологии восприятия. «Он [Л. Веккер] до сих пор отчетливо помнит, как, глядя в окно, задумался о том, почему он видит людей, идущих по улице, там, где они действительно находятся, хотя реально их изображение расположено на сетчатке его глаз. И как, передвигая свои очки на различное расстояние от глаз, наблюдал меняющиеся изображения предмета и удивлялся, что предмет остается одним и тем же, а его образы меняются» [1]. Исходя из того, что «предмет остаётся одним и тем же, а его образы меняются», отметим, что сознанию / психологическому миру человека свойственно воспринимать окружающее посредством «проекций» так или иначе фиксируемых образов.

На «единственности» сознания человека для собственного внутреннего мира основан художественный принцип психологической идентификации [2]. Идентификация в данном случае происходит не между сознаниями продуцирующим и воспринимающим (такая идентификация невозможна в силу кардинальных различий процессов творчества и восприятия), а между сознанием виртуальным (сознанием персонажа) и сознанием воспринимающим (сознанием адресата). Учитывая множественность художественных жанров и направлений, включённых в единый принцип психологической идентифи- 
кации, условимся обозначать воспринимающее сознание термином «адресат». Как адресат функционирует любое воспринимающее сознание, которому адресовано художественное произведение: будь это картина, симфония, напечатанный вербальный текст или сценическая композиция (различаются в данном случае только задействуемые в восприятии рецепторы / органы чувств). Таким образом, складывается принцип психологической идентификации адресата и персонажа.

«Общим знаменателем» единственного внутреннего мира персонажа и единственного - для собственного сознания - внутреннего мира адресата выступают те самые образы, «проекции» действительности на внутренний мир. Поскольку идентичны «проекции» видимого, в процесс идентификации вовлекаются внутренние миры полностью1 . Происходит идентификация психологических процессов: психологические процессы персонажа, как и образы видимого мира, к которым они приводят или из которых исходят, изначально «заданы» в художественном тексте, можно сказать, в виртуальной реальности; психологические процессы адресата «достраивают» виртуальную реальность, создающуюся его воображением при восприятии интенций внутреннего мира персонажа, до тех же образов видимого мира, которые содержатся в художественном тексте и соответственно во внутреннем мире персонажа. Именно на идентичности образов видимого мира в сознании адресата и персонажа строится принцип их психологической идентификации, вершинным, наиболее полным воплощением которого представляется моноопера.

Психологическое пространство личности включает ряд подчинённых областей, объединяемых действием эмоциональности как важнейшего психологического фактора. О важности эмоциональности как психологического фактора говорить представляется излишним - каждый знаком с понятием эмоции на практике. В рамках научных подходов, относящихся к «павловскому направлению в изучении высшей нервной (психической) деятельности мозга» [4. С. 188], возникновение эмоции связывается с понятием потребности, определяемой как «избирательная зависимость живых организмов от факторов внешней среды, существенных для самосохранения и саморазвития, источник активности живых систем, побуждение и цель их поведения в окружающем мире» [4. С. 191]. Однако и в действительной жизни, и в синтетическом художественном тексте монооперы эмоциональность сложно охарактеризовать только через «внешне наблюдаемые проявления эмоций» [4. С. 89]. «Эмоциональные переживания... охватывают... все прочие психические явления. ..."эмоциональное” даёт нам знание о строении... “внутреннего” мира в целом» [4. С. 113]. В данном направлении можно проследить зависимость общего облика внутреннего мира от эмоциональных процессов. Эмоциональными процессами во многом определяется характер цельности внутреннего мира личности как одного из его важнейших параметров. Цельности внутреннего мира способствует также выявляемый в процессах психологической жизни человека «принцип единства эмоционального состояния» [4. С. 55].

\footnotetext{
${ }^{1}$ В действительной жизни различие между позициями в отношении одного и того же предмета базируется именно на различии «проекций», «точек зрения» на предмет.
} 
При переходе от воспринимаемой действительности к художественному тексту, каким является моноопера, вступают в силу закономерности внутренних, интратекстовых взаимосвязей художественных элементов.

Всеобъемлющий внутренний мир персонажа М. Бахтин, например, обозначает как его самосознание, выступающее «как художественная доминанта построения героя» [8. С. 58], отмечая, что «самосознание можно сделать доминантой в изображении всякого человека» [Там же]. Выскажем предположение, что самосознание и является доминантой в существовании, а не только изображении каждого человека. Человек, вне и безотносительно художественного мира, обладает свойством монологичности, сознательно или бессознательно «отмеряет» всё от себя как от начала координат. Не вдаваясь в подробности психологии личности, что не входит ни в круг проблематики статьи, ни в сферу компетенций автора, вспомним о корреляции художественного феномена монологичности с такими внехудожественными явлениями человеческой психики, как апперцепция ${ }^{1}$ [9], психофрактал [10], образ мира [11] и др. На основе данных коррелятов функционирует механизм эмпатии, актуализирующий монологичность как свойство человеческого сознания и ключевое свойство синтетического текста монооперы.

Эмпатия, согласно словарным определениям, представляет собой «способность идентифицироваться с другим человеком, почувствовать то, что он ощущает» [13]; «Эмпатия (от греч. empatheia - сопереживание) - постижение эмоционального состояния, проникновение-вчувствование в переживания другого человека. Термин... введен Э. Титченером, обобщившим развивавшиеся в философской традиции идеи о симпатии с теориями вчувствования Э. Клиффорда и Т. Липпса» [14]. Именно эмпатия обеспечивает действие принципа психологической идентификации адресата и персонажа, опираясь на закономерности одной из сфер психологического пространства личности эмоциональность. Проследим, каким образом происходит идентификация адресата и персонажа именно на эмоциональном уровне.

Внутритекстовым коррелятом и «передаточным механизмом» внутреннего мира персонажа в отношении эмоциональности выступает эмотивность. Эмоции, являющиеся в моноопере «ядром» психологического мира персонажа, трансформируются посредством эмотивности в художественную, текстовую реальность.

Многообразие и разноплановость текстовых элементов, составляющих для синтетического целого монооперы довольно обширное множество, объединяются посредством интегративного фактора эмотивности. Функционирование эмотивности в качестве способа интеграции художественных элементов в тексте монооперы обусловлено самой сущностью данного понятия, воплощающего процесс перехода феномена действительности в текстовую категорию - из экстраязыковой сферы в интраязыковую. «В языковом про-

\footnotetext{
${ }^{1}$ «Представления есть необходимое посредствующее звено, смыкающее первосигнальные и психические процессы, организованные в форму образов различных видов, и второсигнальные мыслительные или речемыслительные психические процессы, составляющие уже «специально человеческий» уровень психической информации... Обязательным посредствующим звеном здесь является... включённость апперцепции, т.е. образов, сформированных в прошлом опыте и воплощённых в тех извлекаемых из памяти эталонах, с которыми сличается каждый актуальный перцепт» [12. С. 159].
} 
цессе эмоциональность как психическое явление трансформируется в эмотивность, которая является уже языковым феноменом» [15. С. 33].

Понятие и термин «эмотивность» принадлежали изначально «новой отрасли лингвистики XX века - эмотиологии» [16]. Эмотиология, в свою очередь, является одной из областей антропоцентрической лингвистики; именно антропоцентрическая линвистика может квалифицироваться как «возвратившая человеку статус “меры всех вещей” и вернувшая его в центр мироздания» [17. С. 64]. «В рамках данной научной парадигмы интересы исследователя “переключаются с объектов познания на субъекта, т.е. анализируется человек в языке и язык в человеке” [18. С. 6]» [19]. Не случайно центрирование позиций и смыслов, находящихся в русле антропоцентрической лингвистики, оказываются так созвучны позициям и смыслам, принадлежащим антропоцентрической мировоззренческой установке, вершинным воплощением которой в искусстве видится моноопера. Не случайно именно эмотивность выступает в моноопере фактором интеграции разноплановых внутритекстовых элементов и центральной областью воплощения внутреннего мира персонажа в синтетическом художественном тексте.

Приведём определение эмотивности, сформулированное В. Шаховским: «...имманентно присущее языку семантическое свойство выражать системой своих средств эмоциональность как факт психики» [15. С. 24]. При адаптации понятия «эмотивность» к языку особого рода - синтетическому языку оперного искусства - возникает ряд новых составляющих данного понятия. Оставаясь «семантическим свойством языка», эмотивность в искусстве обращается К иным фактам эмоциональности, чем язык, рассматриваемый лингвистикой. В искусстве присутствует эмоциональность иного рода. Это объяснимо принадлежностью искусства сфере эстетического осмысления действительности, коррелирующего с постулатами теории вчувствования: эстетическое вчувствование «отличается от общих, повседневных состояний тем, что является интенсивным повышением их» [21]. «Из всех обобщений Фолькельта, думается, нет более бесспорного и более плодотворного, чем его лаконическая формула: "Искусство состоит в развеществлении изображаемого"» [22. С. 69]. Эмоции искусства - «умные эмоции» [22]; опосредованные, небытовые, деперсонализированные эмоции [23]; эмоции, создающиеся посредством «психической дистанции» с действительностью [24]. Именно языковые средства искусства как особая оптика и обусловливают переход эмоциональности как факта психической жизни человека в эмотивность как свойство языка искусства, в котором присутствуют не жизненные, бытовые, конкретные, а «универсальные», прошедшие стадию «развеществления» эмоции.

По С. Ионовой, «наибольшее проявление эмотивность получает в интонационном строе языка (просодии) - системе выразительных средств, реализующихся в речи на всех уровнях речевых сегментов» [24. С. 61]. Именно специфика музыкальной интонации, преобладающей в синтетическом тексте монооперы над речевой, определяет первостепенность для монооперы эмотивного потенциила слова («эмотивными сигналами текста... являются: эмотивное значение, эмотивная коннотация и эмотивный потенциал слова» [25. С. 10]).

Как можно заметить, речевая интонация намного пассивнее музыкальной в отношении передачи эмотива адресату: в вербальном сообщении в боль- 
шинстве случаев предметно-логическая сторона превалирует над эмоциональной ${ }^{1}$. Музыкальная, а тем более вокальная интонация несёт меньшую, чем вербальная, предметно-логическую нагрузку и соответственно бо́льшую эмотивную (вероятно, в связи с тем, что эмотивы действуют на сознание адресата более непосредственно «в музыке как искусстве невербальном, лишённом “точечных" предметных значений» [26. С. 5]). В синтетическом тексте монооперы можно наблюдать динамические процессы «переключений» эмотивной и предметно-логической смысловой нагрузки, обусловленные динамикой взаимодействия «вербального (словесного) и авербального (музыкального) языков» [25. С. 5]. В моноопере наблюдаем нерасторжимое единство вербальной и авербальной смысловой нагрузки, что достаточно неожиданно отсылает к историческим корням человеческой культуры вообще: «одними из довербальных информационных структур... являются эмоции человека» [27. С. 34].

Здесь актуализируется явление, которое автор определяет как «встречные интенции языка» [28]. Свойства музыкального образно-интонационного языка средств выразительности обусловливают первостепенное значение эмотивности в синтетическом тексте монооперы («Интегративная функция эмотивности нацелена на создание образа и как самостоятельного явления, и как компонента музыкально-сценического целого» [29. С. 31]). Эмотивное центрирование внутреннего мира персонажа способствует интенсивности процессов психологической идентификации адресата и персонажа посредством механизма эмпатии.

Эмотивность функционирует в моноопере как первостепенный фактор психологического пространства персонажа - важнейшей для монооперы области внутреннего мира персонажа. Именно эмотивность обеспечивает формирование невербального, подтекстового смыслового пласта синтетического текста монооперы. Констатируя первостепенное значение в моноопере «закадрового», подтекстового смыслового пласта, следует обратиться к классификации типов информации в художественном образе, предложенной И. Гальпериным: содержательно-подтекстовая информация (СПИ), содержательно-фактуальная (СФИ) и содержательно-концептуальная (СКИ). По мнению исследователя, «СПИ представляет собой скрытую информацию, извлекаемую из СФИ благодаря способности единиц языка порождать ассоциативные значения, а также благодаря способности предложений приращивать смыслы... СФИ содержит сообщения о фактах, событиях, процессах... и всегда выражена вербально. СКИ сообщает читателю индивидуальноавторское понимание отношений между явлениями, описанными средствами СФИ, понимание их причинно-следственных связей...» [30. С. 74].

СФИ, как уже было замечено, в моноопере обозначается достаточно скупо, что можно видеть и на конкретных примерах: «Ожидание» А. Шёнберга содержит только одно событие - процесс поиска и страшный финал; в «Человеческом голосе» Ф. Пуленка даже нет чётко очерченного финала, как и в «Ожидании» М. Таривердиева; несколько более

\footnotetext{
${ }^{1}$ Конечно, будет справедливым отметить некоторую некорректность такого сравнения - речевая и музыкальная интонационные сферы функционируют в самодостаточных и не зависящих друг от друга видах искусства; однако данное сопоставление необходимо автору для более чёткого обозначения функций эмотивности в синтетическом целом монооперы.
} 
развёрнуты сюжетные фабулы моноопер «Дневник Анны Франк» Г. Фрида и «Письмо незнакомки» А. Спадавеккиа, однако и в них фактические события только намечены, выступая поводом для внутренней психологической реакции персонажа. СКИ в моноопере выражается только в структурно-драматургической организации текста, так как «индивидуально-авторское» в моноопере скрыто за субъектом единственного персонажа. Первостепенным, несущим функцию «центра притяжения» всех смысловых линий, в моноопере оказывается уровень СПИ, воплощающий эмотивную логику текстового целого.

Внешние явления и события, образующие непосредственно читаемый сюжет произведения, оказываются в данном случае лишь сопутствующими образованиями первичной смысловой линии - либо поводом, либо следствием формирования тех или иных стадий (этапов) первичной линии ${ }^{1}$. В моноопере первичность эмотивного плана подчёркивается нивелированием внешнего действия и значимостью внутреннего мира персонажа.

Именно актуальность и значение для монооперы антропоцентрической мировоззренческой установки - «прародины» понятия эмотивности - тесно связывают эмотивность и монооперу (в большей степени, чем, например, эмотивность и многоперсонажную оперу; эмотивность и инструментальную музыку и др.). Внешне наблюдаемый сюжет в моноопере может быть, как уже говорилось, подчёркнуто минимизирован ${ }^{2}$, может быть богат событиями, излагаемыми наблюдателем и с точки зрения наблюдателя ${ }^{3}$.

Первичным в моноопере выступает сюжет внутренний, сюжет, представляющий собой цепь психологических событий внутреннего мира персонажа; именно события внутреннего мира персонажа составляют первичный сюжет - то, что можно назвать действием монооперы. В центре внимания оказывается цепочка психологических реакций на те или иные стимулы (как поступившие извне, так и сформировавшиеся во внутреннем мире); природа стимулов и их конкретное содержание в данном случае оказываются вторичными, не несущими функции действия. Именно в связи с этим представляется правомерным для монооперы определить внешне наблюдаемый сюжет как вторичный, протекающий параллельно первичному и связанный с ним казуально, но не синхронно (рис. 1).

Как можем заметить, вторичный и первичный сюжеты параллельны, но не синхронизированы: события первичного сюжета не являются прямым следствием событий сюжета вторичного. Схема «стимул $\rightarrow$ реакция» здесь достаточно условна, так как внутренняя психологическая жизнь человека не определяется исключительно внешними причинами и поводами: динамика внутренних психологических процессов зачастую непредсказуема.

\footnotetext{
${ }^{1}$ Схема S $\rightarrow \mathrm{R}$, представляющаяся основной в рамках бихевиоризма [31], оказывается в нашем случае «обращённой»: психологическая реакция персонажа относится к первичной смысловой линии, тогда как стимул если и упоминается в контексте реакции, не является частью смыслового целого монооперы, оставаясь лишь формальным поводом для появления обрисовываемой реакции.

${ }^{2}$ Ни чтение письма, ни пребывание «под часами» не предполагают смены внешне наблюдаемой ситуации: на примере монооперы М. Таривердиева «Ожидание» можно достаточно отчётливо увидеть - меняется не ситуация, меняется отношение к ней.

${ }^{3}$ В монооперах Г. Фрида «Дневник Анны Франк» или А. Спадавеккиа «Письмо незнакомки», что уже отмечалось, видим ряд разнохарактерных эпизодов, но воспринимаемых под одним «углом зрения».
} 


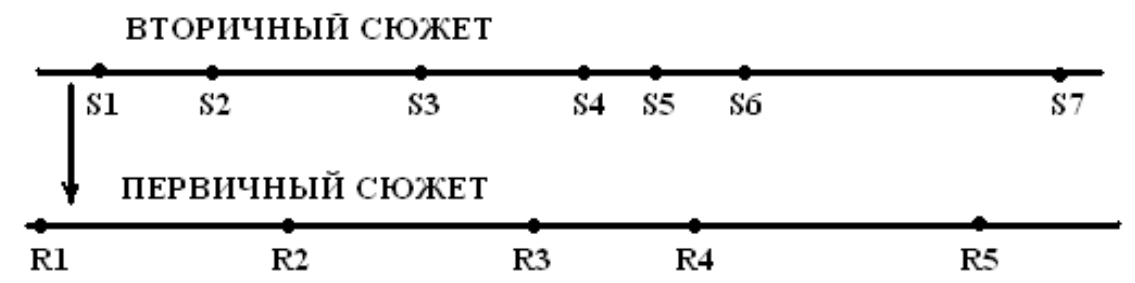

Рис. 1. Соотношение в моноопере первичного и вторичного сюжетов

Подобная функция внутреннего сюжета как первичного отсутствует в многоперсонажной опере по нескольким причинам, озвучим важнейшие из которых.

В первую очередь, внутренний сюжет (психологические события) не может быть первичным в многоперсонажной опере в связи с отсутствием в ней «единственности» персонажа - центрального смыслового ориентира монооперы. Все персонажи оперы существуют в сознании адресата (как ранее и композитора) как наблюдаемые извне объекты; в центре внимания соответственно находятся внешне наблюдаемые действия, высказывания, отношения и др.; внутренний мир любого из персонажей раскрывается лишь эпизодически, посредством сольных высказываний (монологов, рассказов, арий-аффектов и др.). Целостная линия психологических событий во внутреннем мире того или иного персонажа не выстраивается, так как внимание и эмотивная динамика переключаются на других персонажей. Сольные высказывания того или иного персонажа, присутствующие в рамках оперного целого, выступают в качестве «окон» во внутреннее психологическое пространство данного персонажа. Однако эти «окна» формируют фрагментарное, не непрерывное представление о внутреннем мире персонажа, что препятствует процессу психологической идентификации адресата и персонажа; в условиях многоперсонажной оперы названный процесс и не является востребованным художественно.

Целостную хронологически линеарную последовательность психологических событий внутреннего мира персонажса, функционирующую как первичный сюжет монооперы, обозначим как эмотивный план, призванный обеспечить целостность внутреннего мира единственного персонажа монооперы. Подчеркнём, что такое явление, как эмотивный план, возможно фиксировать исключительно в моноопере, так как целостность и неразрывная хронологическая линеарность последовательности психологических событий, неизбежная в действительности, в художественном тексте возможна только при наличии «единственности» персонажа и отсутствии других линий, способных нарушить эту целостность ${ }^{1}$. Наличие целостной линии эмотивного плана в очередной раз свидетельствует о масштабности и значимости жанра монооперы как вершинного проявления антропоцентрической мировоззренческой установки в искусстве.

Зависимость структурных закономерностей текста от первичного сюжета является функииональной связью выражаемого и выражающего: «музыкальная

\footnotetext{
${ }^{1}$ Стремлением к подобной целостности внутреннего мира персонажа (в рамках, как уже говорилось, позиции «я», а не «он/она») объяснимы действия певца-актёра, «домысливающего» не прописанные в тексте поступки и мысли своего персонажа.
} 
форма, говоря метафорически, может быть понята как своего рода проекция художественной идеи (идеального феномена) на интонационную “плоть" (материальный феномен)» [32. С. 34]. «Функциональность - как стройная система связи и взаимодействия контрастных частей - есть важнейший принцип организации всякого многоэлементного целого...» [33]. Именно функциональная связь объединяет структурно-драматургическую организацию синтетического текста той или иной конкретной монооперы со спецификой её индивидуального эмотивного плана (первичного сюжета). Поэтому представляется необходимым очертить внутреннюю структуру эмотивного плана, на которой основывается структурнодраматургическая организация текста монооперы.

Относительно дискретные психологические события внутреннего мира персонажа, составляющие эмотивный план, считаем целесообразным называть эмотивами, «строительными» элементами целостного эмотивного плана (первичного сюжета монооперы). Эмотивный план монооперы образует непрерывную линеарную последовательность, адекватную процессуальной природе музыкально-театральных жанров. Непрерывность линеарной последовательности эмотивного плана обеспечивается участием в смыслообразующих процессах феномена парциального настоящего [34]. Смена эмотивов не обязательно синхронизируется со сменой действия (ряда событий внутреннего мира персонажа); она может быть обусловлена, например, сменой позиций персонажа.

Например, ряд эмотивов, составляющих эмотивный план монооперы М. Таривердиева «Ожидание», можно представить следующим образом:

1) «Вот ведь как, явилась первой...».

2) «Современная женщина».

3) «Героя моего пока что не заметно».

4) «Порой берёт тоска».

5) «А его всё нет».

6) «Скорая помощь».

7) «О, приди же, приди».

8) «Как детство, ночь обнажена».

9) «Птицы спрятаться догадаются».

10) «О, приди же, приди».

11) «Как без тебя, как?».

12) «А его всё нет и нет».

13) «О, приди же, приди».

В моноопере Г. Фрида «Дневник Анны Франк» разделённость эмотивного плана на локальные эмотивы подчёркнута формальным делением целого на дискретные эпизоды-«миниатюры»:

1) Вступление.

2) День рождения.

3) Школа.

4) Разговор с отцом.

5) Повестка из гестапо.

6) «Убежище» (Колокол Вестертурма).

7) У окошка.

8) Мне говорили.

9) Отчаяние. 
10) Воспоминание.

11) $\mathrm{CoH}$.

12) Интерлюдия.

13) Дуэт супругов ван-Даан.

14) Воры.

15) Речитатив.

16) Я вспоминаю Петера.

17. На русском фронте.

18) Облава.

19) Одиночество.

20) Пассакалья.

21) Финал.

Однако моноопера в отличие, например, от цикла миниатюр, не ограничена так или иначе упорядоченным «калейдоскопом» эпизодов экспозиционного характера. В музыкально-сценическом синтетическом тексте ряды отдельных эмотивов объединяются более масштабными образованиями, которые обозначаем как эмотивные цеентры.

Эмотивные центры могут быть хронологически «рассредоточены» по тексту, связывая несколько эмотивов «арочным» методом; могут, при соответствующей смысловой необходимости, представлять собой протяжённые эпизоды. В любом случае эмотивные центры реализуют механизм повторности, объединяя ряд эмотивов в оправданную смысловой необходимостью целостность. Образованию подобных целостностей способствует организация хронотопа монооперы на основе парциального настоящего [34], которое служит неотъемлемой частью психологического времени личности (в данном случае персонажа [35]).

Например, учитывая, что мечта и воспоминание о той же мечте (воплощённой или нет) представляют собой два самостоятельных эмотива ${ }^{1}$, они составляют единый эмотивный центр. Данный эмотивный центр может быть хронологически соединён, может быть хронологически рассредоточен:

$$
\begin{aligned}
& \text { ряд других действий } \rightarrow \text { мечта } \rightarrow \text { воспоминание } \rightarrow \text { ряд других действий } \\
& \text { или } \\
& \text { ряд других действий } \rightarrow \text { мечта } \rightarrow \text { ряд других действий } \rightarrow \text { воспоминание } \rightarrow \\
& \text { ряд других действий. }
\end{aligned}
$$

В первом случае видим хронологически сконцентрированное смысловое единство, во втором - систему смысловых «арок», реализующих в тексте механизм повторности.

Эмотивные центры, объединяющие ряд эмотивов, включены в более масштабные эмотивные сферы. Эмотивные сферы не располагают прямыми текстовыми коррелятами (ни языковыми, ни структурными), но выступают аналогом сил действия и контрдействия, наблюдаемых, как правило, в многоперсонажной опере (рис. 2).

\footnotetext{
${ }^{1}$ Примеры произвольны; аналогичными эмотивными центрами могут быть, например, образ любимой/любимого, пара эмотивов «встреча - расставание» или «разлука - встреча» и др.

${ }^{2}$ Отметим, что приведёнными вариантами их множество не исчерпывается.
} 


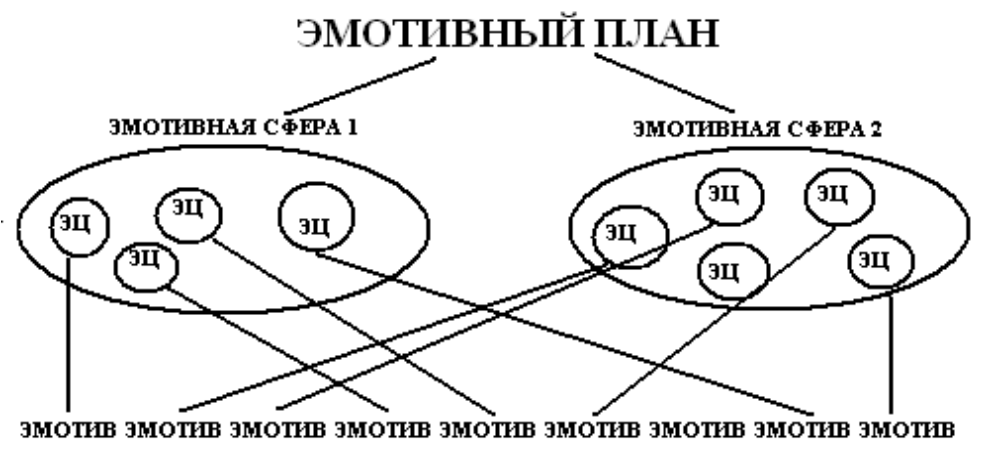

Рис. 2. Структура эмотивного плана (эмотивные сферы, эмотивные центры (ЭЦ), эмотивы)

Классификация эмотивных центров усложняется тем, что нет чётких соответствий «номер = афффект = эмотивный цеентр»; как и происходит преимущественно в действительности - в тексте монооперы эмотивные центры имеют свойство пересекаться и перерастать друг в друга; особенно ярко такую закономерность можно увидеть, например, в номере «Пассакалья» (моноопера Г. Фрида «Дневник Анны Франк»), где сам жанр (пассакалья) говорит о трагичности ситуации, а слова и вокальная партия - о вере в будущее, которого нет. По другому принципу, чем в эмотивных сферах, происходит объединение эпизодов в эмотивный центр. «Убежище (Колокол Вестертурма)» и по вербальной составляющей, и по интонационной линии вокальной партии относится к эмотивной сфере воли к жизни; однако эмотивный центр здесь задействован другой - эмотивный центр, объединяющий «Убежище (Колокол Вестертурма)» с эпизодом «Сон», а в дальнейшем - с эпизодом «Пассакалья». Данный эмотивный центр охватывает три разноплановых эмотива, восходящих к единому состоянию - состоянию страха перед Неведомым, запредельным, нечеловеческим. Эмотивные сферы являются, по сути, о чём уже говорилось, отражением сил действия и контрдействия, отражением идейного конфликта произведения, тогда как эмотивные центры - более локальные составляющие - представляют собой различные стороны отношения персонажа к происходящему. Например, если эмотивные сферы представляют собой Добро и Зло (что желаемо и что не желаемо личностью), эмотивные центры реализуют «лики» Добра и Зла. Злом в моноопере «Дневник Анны Франк» является всё, что связано с несвободой, заключением, угрозой - хотя это зло многолико, от страха («Воры», «Облава») до тоски о прошлом («Воспоминание», «Речитатив») и масштабных философских выводов («Пассакалья»). Более того, если эмотивные сферы представляются исключительно идейно-содержательными, эмотивные центры имеют и языковую сторону реализации.

«Будучи неразрывно связана с сюжетом ${ }^{1}$, музыка в опере ${ }^{2}$ представляет собой только компонент синтетического целого, но компонент ведущий: это не просто одно из слагаемых, но определяющий фактор оперного спектакля» [36. С. 78]. Если такое замечание справедливо для многоперсонажной оперы,

\footnotetext{
${ }^{1}$ В нашем случае с сюжетом первичным, т.е. с эмотивным планом.

${ }^{2}$ В нашем случае и в моноопере также.
} 
в моноопере данная закономерность усиливается благодаря центральному значению подтекстовых, зачастую невербальных смыслов. Музыкальным воплощением эмотивного центра можно считать интонационно-тематический комплекс, динамика «арок», повторов и развития в котором составляет тематическую драматургию [36] конкретного синтетического текста. Интонационно-тематический комплекс выступает языковым коррелятом эмотивного центра. Во-первых, именно посредством интонационно-тематического комплекса в синтетическом тексте реализуется принцип повторности как организации структуры; во-вторых, посредством интонационно-тематического комплекса реализуется динамика преобразований и «перерождений» темы вплоть до своей смысловой противоположности («повторность как принцип формообразования» [37. С. 41]). «Повторность как общий принцип имеет множество более частных градаций:

1) повтор точный;

2) повтор с перетекстовкой (иное вербальное наполнение);

3) повтор перенаправленный (другой голос - другой персонаж - хор);

4) повтор инструментальный / вокальный: проведение вокальной темы у оркестра или наоборот;

5) повтор с переинструментовкой (иные оркестровые краски);

6) повтор в других регистрах;

7) повтор в другой динамике;

8) повтор в другом темпе;

9) повтор с перегармонизацией;

10) и т.д. (повтор со сменой тех или иных средств выразительности, но сохранением узнаваемого мелодического или ритмического облика темы)» [38. C. 53].

Перенаправленный повтор, возможный в многоперсонажной опере, невозможен в жанре монооперы в принципе, так как в ней нет ни других персонажей, ни хора; повтор инструментальный / вокальный, напротив, представляет собой основу действия в тексте единой языковой системы - языкового спектра монооперы [39].

Итак, при построении эмотивного плана - первичного сюжета монооперы смысловые и внутритекстовые характеристики конкретного воплощения жанрового инварианта приходят в соответствие. В воплощении эмотивного плана (смысловой категории) задействуются как языковой спектр монооперы, так и структурно-драматургическая организация текста. Именно на уровне текста можно проследить, как при воплощении смысловой категории эмотивного плана (первичного сюжета монооперы) задействуются обе составляющие (языковая и структурная) жанрового инварианта монооперы - все, так или иначе «работающие» компоненты жанра оказываются в нерасторжимом единстве, которое лишь условно - при исследовании текста - можно разделить на те или иные «слагаемые». Названное единство действует на всех уровнях первичного сюжета монооперы - эмотивного плана: на уровнях эмотивных центров и каждого отдельного эмотива (эмотивные сферы являются более общими и внетекстовыми, идейно-образными категориями). 


\section{Литература}

1. Магун В.С. Об авторе этой книги (вступительная статья) // Веккер Л.М. Психика и реальность: единая теория психических процессов. М.: Смысл, 1998. 685 с.

2. Приходовская Е.А. Идентификация сознания персонажа и внутреннего мира слушателя в жанре монооперы // Таврический научный обозреватель. 2016. № 10 (15). Ч. І. С. 125-131.

3. Симонов П.В. Информационная теория эмоций // Психология эмоций / под ред. В.К. Вилюнаса, Ю.Б. Гиппенрейтер. М.: Изд-во Моск. ун-та, 1993. С. 188-195.

4. Психология эмоций. Тексты. 2-е изд. / под ред. В.К. Вилюнаса, Ю.Б. Гиппенрейтер. М.: Изд-во Моск. ун-та, 1993. 304 с.

5. James W. What is an emotion? // Mind. 1884. Vol. 9, № 34. Р. 188-205 // Психология эмоций / под ред. В.К. Вилюнаса, Ю.Б. Гиппенрейтер. М.: Изд-во Моск. ун-та, 1993. С. 86-98.

6. Krueger F. Das Wesen der Gefühle. Entrourf eines systematischen. Theorie. 3-e \& 4-e unveranderte aufl. Leipzig, 1980. S. 2-37 // Психология эмоций / под ред. В.К. Вилюнаса, Ю.Б. Гиппенрейтер. М.: Изд-во Моск. ун-та, 1993. С. 113-124.

7. Вундm B. Основы физиологической психологии: Об элементах душевной жизни. Интенсивность ощущения / пер. с нем. М. : URSS, 2010. 330 с.

8. Бахтин M.M. Проблемы поэтики Достоевского. М.: Сов. писатель, 1963. 362 с.

9. Лейбнии Г. Новые опыты о человеческом разумении // Лейбниц Г. Сочинения: в 4 т. Т. 2. М.: Мысль, 1983. 686 с.

10. Донченко E.A. Фрактальная психология (Доглубинные основания индивидуальной и социетальной жизни). Киев: Знания, 2005. 323 с.

11. Леонтьев А.Н. Психология образа // Вестник Московского университета. Серия 14: Психология. 1979. № 2. С. 12-13.

12. Веккер Л.М. Психика и реальность: единая теория психических процессов. М.: Смысл, 1998. $685 \mathrm{c}$. 2008.

13. Краткий толковый психолого-психиатрический словарь / под ред. К. Игишева. М.,

14. Краткий психологический словарь / ред. Л.А. Карпенко, А.В. Петровский, М.Г. Ярошевский. Ростов н/Д: Феникс, 1998. 512 с.

15. Шаховский В.И. «Эмоции с точки зрения лингвистики» // Музыка начинается там, где кончается слово. Астрахань; Москва, 1995. С. 30-33.

16. Исхакова 3.3. Эмотивный дейксис и его декодирование в семиосфере: дис. ... д-ра филол. наук. Уфа, 2012. 414 с.

17. Воркачёв С.Г. Становление антропоцентрической парадигмы в языкознании // Филологические науки. 2001. № 1. С. 64-72.

18. Маслова В.А. Лингвокультурология: учеб. пособие для студ. высш. учеб. заведений. М.: Изд. центр «Академия», 2001. 208 с.

19. Кущева О.Ю. Антропоцентрическая парадигма в современной лингвистике // Вестник Адыгейского государственного университета. 2006. № 4. С. 155-156.

20. Volkelt J. Gewissheit und Wahrheit. Munchen: Beck, 1918. 134 p.

21. Vygotskiy L.S. Psikhologiya iskusstva. M .: Iskusstvo, 1986. $326 \mathrm{s.}$

22. Ortega-i-Gasset KH. Degumanizatsiya iskusstva // Ortega-i-Gasset KH. Estetika. Filosofiya kul'tury / vstup. St. G.M. Frindlera; Sost. V.Ye. Bagno. M .: Iskusstvo, 1991. S. 218-260oC.

23. Langer S. Oshchushcheniye i forma: novaya teoriya iskusstva. New York, 1953. 433 p.

24. Ионова С.В. Эмотивность текста как лингвистическая проблема: дис. ... канд. искусствоведения. М., 2005. 205 с.

25. Волкова П.С. Эмотивность как средство интерпретации смысла художественного текста (на материале прозы Н.В. Гоголя и музыки Ю. Буцко, А. Холминова, Р. Щедрина): автореферат дис. ... канд. филол. наук. Волгоград, 1997. 22 с.

26. Коляденко Н.П. Синестетичность музыкально-художественного сознания: на материале искусства ХХ века. Новосибирск : Новосиб. гос. консерватория, 2005. 392 с.

27. Шаховский В.И. Лингвистическая теория эмоций: М.: Гнозис, 2008. 416 с.

28. Приходовская Е.A. Встречные интенции языка : к вопросу творческих поисков и решений композитора // Теория и практика общественного развития. 2014. № 5. С. 144-147.

29. Приходовская Е.A. Камерно-вокальные и вокально-сценические произведения : творческая практика композитора : дис. ... канд. искусствоведения. Новосибирск, 2010. 353 с.

30. Гальперин И.Р. Текст как объект лингвистического исследования / И.Р. Гальперин. М.: Наука, 1981. 139 с. 
31. Андреева Г.М. Зарубежная социальная психология ХХ столетия: Теоретические подходы: учеб. пособие для вузов / Г.М. Андреева, Н.Н. Богомолова, Л.А. Петровская. М. : Аспект Пресс, 2002. 287 c.

32. Бобровский В.П. Функциональные основы музыкальной формы : Исследование. 2-е изд., доп. М.: URSS, 2012. 338 с.

33. Григорьев С.С. О мелодике Римского-Корсакова. М.: Музгиз, 1961. 196 с.

34. Головаха Е.И. Психологическое время личности. Киев: Наукова думка, 1984. 210 с.

35. Приходовская E.A. Специфика хронотопа в жанре оперы // European Social Science Journal. 2014. № 8 (т. 2). С. 205-211.

36. Чигарёва Е.И. О тематической драматургии в опере Моцарта «Дон-Жуан» // Вопросы оперной драматургии. М., 1975. С. 78-117.

37. Асафьев Б.В. Музыкальная форма как процесс. Кн. 1-я и 2-я. Л. : Музгиз, 1963. 379 с.

38. Приходовская E.A. Оперная драматургия: учеб. пособие. СПб.: Лань; ПЛАНЕТА МУзЫКИ, 2015. $80 \mathrm{c.}$

39. Приходовская Е.A. Система вокальных средств выразительности в музыкальной языковой семье // European Social Science Journal. 2014. № 9 (т. 1). С. 300-305.

Prikhodovskaya Ekaterina A. Tomsk State University (Tomsk, Russian Federation).

E-mail: prihkatja@mail.ru

Tomsk State University Journal of Cultural Studies and Art History, 2017 (26), pp. 111- 125.

DOI: $10.17223 / 22220836 / 26 / 12$

\section{THE EMOTIVNY PLAN IS A PRIMARY PLOT OF THE MONOOPERA}

Key words: monoopera, emotivity, psychological identification, character.

The consciousness / the psychological world of a person is inclined to perceiving the surrounding reality by means of "projections", the images fixed somewhere. The art principle of psychological identification is based on "uniqueness" of consciousness of the person for his or her own inner world. The identification happens between the virtual consciousness (that of the character) and the perceiving consciousness (that of the addressee). The "projections" of the reality to an inner world act as a "common denominator" for both the only inner world of the character and the inner world of the addressee. As "projections" of the seen are identical - the inner worlds are completely involved in the process of identification (in real life distinction between positions concerning the same subject is based on the difference of "points of view" on the subject). There is an identification of psychological processes: psychological processes of the character, as well as images of the visible world to which they lead or from which proceed - "are initially set" in the literary text, so to say - in virtual reality; psychological processes of the addressee "complete" the virtual reality which is created in his imagination at the perception of intensions of the inner world of the character - up to the same images of the visible world which the literary text contains and, respectively, the inner world of the character does too. The principle of psychological identification is based on identity of images of the visible world in consciousnesses of the addressee and character and its topmost fullest embodiment is monoopera. The Emotivity functions in the monoopera as a paramount factor of psychological space of the character. The external phenomena and events forming directly readable plot of the work appear only as accompanying formations of primary semantic line - either an occasion, or a consequence of formation of these or those stages (stages) of primary line. Creating the emotive plan - primary plot of the monoopera - semantic and intra text characteristics of a concrete embodiment of a genre invariant come to compliance. Both the language layer of the monoopera, and the structural and dramaturgic organization of the text are involved in an embodiment of the emotive plan (semantic category). Everything, all the components of the genre appear in indissoluble unity which is only artificially is possible to divide for the research of the text. The unity mentioned above acts at all levels of primary plot of the monoopera, the emotive plan, at the levels of the emotive of the centers and each separate emotive (emotive spheres are more general and extra text, ideological and figurative categories).

\section{References}

1. Magun, V.S. (1998) Ob avtore etoy knigi (vstupitel'naya stat'ya) [About the author of this book (Introduction)]. In: Vekker, L.M. Psikhika i real'nost': edinaya teoriya psikhicheskikh protsessov [Psychic and reality: a unified theory of mental processes]. Moscow: Smysl. 
2. Prikhodovskaya, E.A. (2016) Identifikatsiya soznaniya personazha i vnutrennego mira slushatelya $\mathrm{v}$ zhanre monoopery [Identification of the character consciousness and the listener's inner world in the genre of monoopera]. Tavricheskiy nauchnyy obozrevatel'. 10(15/1). pp. 125-131.

3. Simonov. P.V. (1993) Informatsionnaya teoriya emotsiy [Information theory of emotions]. In: Vilyunas, V.K. \& Gippenreyter, Yu.B. (eds) Psikhologiya emotsiy [Psychology of emotions]. Moscow: Moscow State University. pp. 188-195.

4. Vilyunas, V.K. \& Gippenreyter, Yu.B. (eds) (1993) Psikhologiya emotsiy [Psychology of emotions]. Moscow: Moscow State University.

5. James, W. (1993) What is an emotion? In: Vilyunas, V.K. \& Gippenreyter, Yu.B. (eds) Psikhologiya emotsiy [Psychology of emotions]. Moscow: Moscow State University. pp. 86-98.

6. Krueger, F. (1993) Das Wesen der Gefühle. Entrourf eines systematischen. Theorie. In: Vilyunas, V.K. \& Gippenreyter, Yu.B. (eds) Psikhologiya emotsiy [Psychology of emotions]. Moscow: Moscow State University. pp. 113-124.

7. Wundt, W. (2010) Osnovy fiziologicheskoy psikhologii: Ob elementakh dushevnoy zhizni. Intensivnost' oshchushcheniya [Fundamentals of physiological psychology: On the elements of psychic life. Intensity of sensation]. Translated from German. Moscow: URSS.

8. Bakhtin, M.M. (1963) Problemy poetiki Dostoevskogo [Problems of Dostoevsky's poetics]. Moscow: Sovetskiy pisatel'.

9. Leibniz, G. (1983) Sochineniya: v 4 t. [works. In 2 vols]. Vol. 2. Moscow: Mysl'.

10. Donchenko, E.A. (2005) Fraktal'naya psikhologiya (Doglubinnye osnovaniya individual'noy $i$ sotsietal'noy zhizni) [Fractal psychology (The deep foundation of individual and societal life)]. Kyev: Znaniya.

11. Leontiev, A.N. (1979) Psikhologiya obraza [Psychology of image]. Vestnik Moskovskogo universiteta. Seriya 14: Psikhologiya - The Moscow University Herald. Series 14: Psychology. 2. pp. 12-13.

12. Vekker, L.M. (1998) Psikhika i real'nost': edinaya teoriya psikhicheskikh protsessov [Psychic and reality: a unified theory of mental processes]. Moscow: Smysl.

13. Igishev, K. (ed.) (2008) Kratkiy tolkovyy psikhologo-psikhiatricheskiy slovar' [The Brief Explanatory Psycho-psychiatric Dictionary]. Moscow: [s.n.].

14. Karpenko, L.A., Petrovskiy, A.V. \& Yaroshevskiy, M.G. (eds) (1998) Kratkiy psikhologicheskiy slovar' [Brief Psychological Dictionary]. Rostov-on-Don: Feniks.

15. Shakhovskiy, V.I. (1995) Emotsii s tochki zreniya lingvistiki [Emotions viewed by linguistics]. In: Kazantseva, L.P. et al. Muzyka nachinaetsya tam, gde konchaetsya slovo [Music begins where words end]. Astrakhan; Moscow: Konservatoriya. pp. 30-33.

16. Iskhakova, Z.Z. (2012) Emotivnyy deyksis i ego dekodirovanie v semiosfere [Emotional deixis and its decoding in the semiosphere]. Philology Dr. Diss. Ufa.

17. Vorkachev, S.G. (2001) Stanovlenie antropotsentricheskoy paradigmy v yazykoznanii [Formation of the anthropocentric paradigm in linguistics]. Filologicheskie nauki. 1. pp. 64-72.

18. Maslova, V.A. (2001) Lingvokul'turologiya [Kinguistic and Cultural Studies]. Moscow: Akademiya.

19. Kushcheva, O.Yu. (2006) The anthropocentric paradigm in modern linguistics. Vestnik Adygeyskogo gosudarstvennogo universiteta - The Bulletin of the Adyghe State University. Series "Philology and the Arts”. 4. pp. 155-156. (In Russian).

20. Volkelt, J. (1918) Gewissheit und Wahrheit [Certainty and Truth]. Munich: Beck.

21. Vygotsky, L.S. (1986) Psikhologiya iskusstva [Psychology of art]. Moscow: Iskusstvo.

22. Ortega y Gasset, H. (1991) Estetika. Filosofiya kul'tury [Aesthetics. Philosophy of Culture]. Translated by O.V. Zhuravlev. Moscow: Iskusstvo. pp. 218-260.

23. Langer, S. (1953) Feeling and form: The new theory of art. New York: Charles Scribner's Sons.

24. Ionova, S.V. (2005) Emotivnost' teksta kak lingvisticheskaya problema [Emotivness of the text as a linguistic problem]. Arts Studies Cand. Diss. Moscow.

25. Volkova, P.S. (1997) Emotivnost' kak sredstvo interpretatsii smysla khudozhestvennogo teksta (na materiale prozy N.V. Gogolya i muzyki Yu. Butsko, A. Kholminova, R. Shchedrina) [Emotivness as a means of interpreting an artistic text (a case study of Nikolai Gogol's prose and music by Yu. Butsko, A. Kholminov, R. Shchedrin)]. Philology Cand. Diss. Volgograd.

26. Kolyadenko, N.P. (2005) Sinestetichnost' muzykal'no-khudozhestvennogo soznaniya: na materiale iskusstva XX veka [Synesthetics of music and artistic consciousness: On the material of the twentieth-century art]. Novosibirsk: Novosibirsk State Conservatory.

27. Shakhovskiy, V.I. (2008) Lingvisticheskaya teoriya emotsiy [Linguistic theory of emotions]. Moscow: Gnozis. 
28. Prikhodovskaya, E.A. (2014) Cross-intentions of a language: Concerning the creative activity of a composer. Teoriya i praktika obshchestvennogo razvitiya - Theory and Practice of Social Development. 5. pp. 144-147. (In Russian).

29. Prikhodovskaya, E.A. (2010) Kamerno-vokal'nye i vokal'no-stsenicheskie proizvedeniya : tvorcheskaya praktika kompozitora [Chamber-vocal and vocal-scenic works: Creative practices of the composer]. Art Studies Cand. Diss. Novosibirsk.

30. Galperin, I.R. (1981) Tekst kak ob"ekt lingvisticheskogo issledovaniya [Text as an object of linguistic research]. Moscow: Nauka.

31. Andreeva, G.M., Bogomolova, N.N. \& Petrovskaya, L.A. (2002) Zarubezhnaya sotsial'naya psikhologiya XX stoletiya: Teoreticheskie podkhody [Foreign social psychology of the twentieth century: Theoretical approaches]. Moscow: Aspekt Press.

32. Bobrovskiy, V.P. (2012) Funktsional'nye osnovy muzykal'noy formy [Functional basis of musical form]. 2nd ed. Moscow: URSS.

33. Grigoriev, S.S. (1961) O melodike Rimskogo-Korsakova [About the melodics of RimskyKorsakov]. Moscow: Muzgiz.

34. Golovakha, E.I. (1984) Psikhologicheskoe vremya lichnosti [Psychological time of personality]. Kyev: Naukova dumka.

35. Prikhodovskaya, E.A. (2014) Spetsifika khronotopa v zhanre opery [Specificity of chronotope in opera]. European Social Science Journal. 8(2). pp. 205-211.

36. Chigareva, E.I. (1975) O tematicheskoy dramaturgii v opere Motsarta "Don-Zhuan" [On thematic drama in Mozart's "Don Juan"]. In: Tyulin, Yu.N. (ed.) Voprosy opernoy dramaturgii [Questions of opera drama]. Moscow: Muzyka. pp. 78-117.

37. Asafiev, B.V. (1963) Muzykal'naya forma kak protsess [Musical form as a process]. Leningrad: Muzgiz.

38. Prikhodovskaya, E.A. (2015) Opernaya dramaturgiya [Opera drama]. St. Petersburg: Lan'; PLANETA MUZYKI.

39. Prikhodovskaya, E.A. (2014) Sistema vokal'nykh sredstv vyrazitel'nosti v muzykal'noy yazykovoy sem'e [The system of vocal means of expressiveness in a musical language family]. European Social Science Journal. 9(1). pp. 300-305. 